\title{
Titanium effect on the microstructure and properties of laminated high boron steel plates
}

\author{
Lin-lin Yuan ${ }^{1)}$, Jing-tao Han ${ }^{1)}$, Jing Liu ${ }^{1)}$, Dong-bin $\mathrm{Wei}^{2)}$, and Mehari Zelalem Abathun ${ }^{1)}$ \\ 1) School of Materials Science and Engineering, University of Science and Technology Beijing, Beijing 100083, China \\ 2) School of Electrical, Mechanical and Mechatronic Systems, University of Technology, Sydney, Sydney NSW 2007, Australia \\ (Received: 17 September 2014; revised: 30 December 2014; accepted: 31 December 2014)
}

\begin{abstract}
High-boron steel is an important material used for thermal neutron shielding. The appropriate amount of added boron must be determined because excessive boron may deteriorate the steel's workability. A uniform microstructure can be formed by adding titanium to boron steel. In this study, casting and hot rolling were used to fabricate laminated high-boron steel plates whose cores contained $2.25 \mathrm{wt} \%$ boron and $0 \mathrm{wt} \%-7.9 \mathrm{wt} \%$ titanium. The effects of titanium content and hot-rolling and heat-treatment processes on the microstructure and properties of the laminated plates were studied. The results indicated that the optimum titanium content was $5.7 \mathrm{wt} \%$ when the boron content was $2.25 \mathrm{wt} \%$, and that the best overall properties were obtained after heat treatment at $1100^{\circ} \mathrm{C}$ for $4 \mathrm{~h}$. The tensile strength, yield strength, and elongation at the specified temperature and holding time were as high as $526.88 \mathrm{MPa}, 219.36 \mathrm{MPa}$, and $29 \%$, respectively.
\end{abstract}

Keywords: boron steel; laminated materials; titanium; boride; hot rolling; heat treatment

\section{Introduction}

Boron is an effective element for shielding thermal neutrons and capturing gamma rays because natural boron contains approximately $19.9 \mathrm{at} \%{ }^{10} \mathrm{~B}$. This isotope, which has a neutron absorption cross-section of 3840 barns, is responsible for absorbing thermal neutrons. However, because of the high price of the ${ }^{10} \mathrm{~B}$ raw material, ${ }^{10} \mathrm{~B}$-rich compounds are not commonly used [1-3]. Stainless steel is also able to shield gamma rays; thus, the thermal stability, corrosion resistance, and neutron-shielding ability of stainless steel can be improved by the addition of boron. However, the solubility of boron in iron is very low $(0.0021 \mathrm{wt} \%$ in $\alpha-\mathrm{Fe}$ and $0.0082 \mathrm{wt} \%$ in $\gamma-\mathrm{Fe}$ at $900-925^{\circ} \mathrm{C}$ ) [4]. According to Grebennikov et al. [5], chromium-nickel steel with $1.5 \mathrm{wt} \%-2.0 \mathrm{wt} \%$ boron exhibits high hardness, low plasticity, poor workability, and poor hot formability. Accordingly, some researchers have attempted to prepare high-boron steel with excellent neutron shielding ability and high strength [6-7]. Stainless steels with $1 \mathrm{wt} \%-2 \mathrm{wt} \%$ of boron have been used for years as thermal neutron shielding materials for control rods and power reactors and as storage racks for nuclear wastes [8]. Sumitomo Metal Industries, Ltd. developed two steel grades, NAR-304BN1 and NAR-304BN3, by adding boron to SUS304 steel, and welded tubes made of these two materials have been reported to satisfy the requirements for nuclear fuel storage [9]. However, detailed information is not available.

A large number of brittle borides $\mathrm{M}_{2} \mathrm{~B}$ (where $\mathrm{M}$ represents $\mathrm{Fe}, \mathrm{Cr}$, or $\mathrm{Mn}$ ) distribute along the grain boundaries in high-boron steel [10]. Two strategies have been developed to improve the formability of high-boron steel without reducing the boron content. The first is to change the size and shape of the boride using various methods. The second is to reduce the volume of the boride by adding strong boride-forming elements [4]. Powder metallurgy and rapid solidification techniques have been used to reduce the formation of $\mathrm{M}_{2} \mathrm{~B}$ networks [11], but only limited progress was made and the formation of a eutectic boride network along the grain boundaries could not be fully eliminated. The formation of $\mathrm{TiB}_{2}$ particles, which have a high melting point, via the addition of titanium to high-boron steel was observed 
to be beneficial for improving the steel's plasticity $[3,5,12]$. With increasing Ti/B atomic ratio, the boron phase in chromium steel changes in the sequence $(\mathrm{Cr}, \mathrm{Fe})_{2} \mathrm{~B} \rightarrow(\mathrm{Cr}, \mathrm{Fe})_{2} \mathrm{~B}$ $+\mathrm{TiB}_{2} \rightarrow \mathrm{TiB}_{2}+(\mathrm{Cr}, \mathrm{Fe})_{2} \mathrm{~B} \rightarrow \mathrm{TiB}_{2}$.

In a previous study [13], the optimum boron content added to steel was determined to be $2.25 \mathrm{wt} \%$. In this paper, high-boron laminated plates with $2.25 \mathrm{wt} \%$ boron were fabricated by casting and hot rolling and were subsequently heat-treated. The effects of the titanium content and the hot-rolling and heat-treatment processes on the microstructures and properties of the laminated plates are presented.

\section{Experimental procedure}

For these experiments, the starting materials were 304 stainless steel, ferroboron alloy $(20.41 \mathrm{wt} \%$ boron and $0.62 \mathrm{wt} \%$ impurities), industrial pure nickel $(0.1 \mathrm{wt} \%$ impurities), pure chromium $(0.12 \mathrm{wt} \%$ impurities $)$, pure manganese $(0.125 \mathrm{wt} \%$ impurities $)$, and commercial pure titanium (0.21wt \% impurities).

The raw materials for the core and clad were melted in a $10-\mathrm{kg}$ vacuum induction furnace filled with pure argon $(99.99 \mathrm{vol} \%)$ and then poured into a cast-iron mold for the laminated casting. The chemical compositions of the coating layer and the core layer of four samples are listed in Table 1. The blanks were then forged at $1150^{\circ} \mathrm{C}$ for subsequent hot-rolling at $1150-950^{\circ} \mathrm{C}$. To adequately break the casting structures, the first two reductions ranged from $20 \%$ to $30 \%$ and the subsequent reduction during each pass was reduced to $15 \%$. The final thickness of the laminated blanks was 3 $\mathrm{mm}$. To ensure the workability of the materials, the samples were reheated at temperatures below $950^{\circ} \mathrm{C}$ for hot-rolling. The hot-rolled blanks were maintained at $1100^{\circ} \mathrm{C}$ for $2,3,4$, and $5 \mathrm{~h}$ before being water-quenched.

X-ray diffraction (XRD) and scanning electron microscopy (SEM) in conjunction with energy-dispersive X-ray spectrometry (EDS, ZEISS ULTRA 55) were used to examine the phases and microstructures of the samples, respectively. We subjected the specimens to tensile-shear tests at room temperature and at a crosshead speed of 0.5 $\mathrm{mm} / \mathrm{min}$ to determine the mechanical properties of the laminated high-boron steel plates.

Table 1. Chemical composition of the coating layer and core layer

\begin{tabular}{cccccccccc}
\hline Sample & $\mathrm{Cr}$ & $\mathrm{Ni}$ & $\mathrm{Si}$ & $\mathrm{Mn}$ & $\mathrm{B}$ & $\mathrm{C}$ & $\mathrm{Ti}$ & $\mathrm{Fe}$ \\
\hline Coating layer & 19.20 & 8.10 & 0.51 & 1.13 & - & 0.15 & - & Balance \\
Core layer of sample 1 & 19.23 & 14.00 & 0.75 & 2.00 & 2.25 & 0.14 & - & Balance \\
Core layer of sample 2 & 19.20 & 14.07 & 0.73 & 1.98 & 2.20 & 0.15 & 2.20 & Balance \\
Core layer of sample 3 & 19.21 & 14.10 & 0.75 & 2.10 & 2.25 & 0.15 & 5.70 & Balance \\
Core layer of sample 4 & 19.22 & 14.05 & 0.74 & 2.03 & 2.26 & 0.15 & 7.90 & Balance \\
\hline
\end{tabular}

\section{Results and discussion}

\subsection{Microstructures of core layers}

SEM micrographs of the as-cast core layers with different titanium contents are shown in Fig. 1. The casting microstructures changed significantly with increasing Ti content. According to the XRD results [14], the smooth strips in the core of sample 1 , which did not contain $\mathrm{Ti}$, were $(\mathrm{Fe}, \mathrm{Cr})_{2} \mathrm{~B}$ and the matrix was pure. When $2.25 \mathrm{wt} \%$ titanium was added, the long strips of $(\mathrm{Fe}, \mathrm{Cr})_{2} \mathrm{~B}$ decreased and turned coarse. Moreover, the concentrated $(\mathrm{Fe}, \mathrm{Cr})_{2} \mathrm{~B}$ strips became separate and internal cracks were observed. However, long $(\mathrm{Fe}, \mathrm{Cr})_{2} \mathrm{~B}$ strips were difficult to observe in the core layers of samples 3 and 4 . The dark boride formed, and its concentration increased constantly with increasing amount of titanium added. We observed that this boride initially formed as particles but progressed to petal-shaped precipitates. On the basis of the XRD analysis, the dark boride was confirmed to be $\mathrm{TiB}_{2}$ and it was observed to be increasingly dispersed with increasing Ti content.

The combination of SEM and EDS analysis results (see Fig. 2 and Fig. 3) reveal that the boron-containing precipitate results in composition segregation. Chromium in the core layer of sample 3 was concentrated on the long boride strips, whereas this element was evenly distributed in the matrix of the core layer of sample 4 .

The standard Gibbs free energy is expressed as follows [15]:

$$
\begin{aligned}
& \Delta G_{T}^{\ominus}=\Delta H_{T}^{\ominus}-T \Delta S_{T}^{\ominus}= \\
& \Delta H_{298}^{\ominus}+\int_{298}^{T} \Delta C_{p} \mathrm{~d} T-T\left(\Delta S_{298}^{\ominus}+\int_{298}^{T} \Delta C_{p} \mathrm{~d} \ln T\right)
\end{aligned}
$$

where $\Delta H_{T}^{\ominus}$ and $\Delta S_{T}^{\ominus}$ are the changes in enthalpy and entropy of two states, respectively, $\Delta H_{298}^{\ominus}$ and $\Delta S_{298}^{\ominus}$ are the standard enthalpy and entropy, respectively, $\Delta C_{p}$ is the specific heat difference between two states, and $T$ is the reaction temperature. 

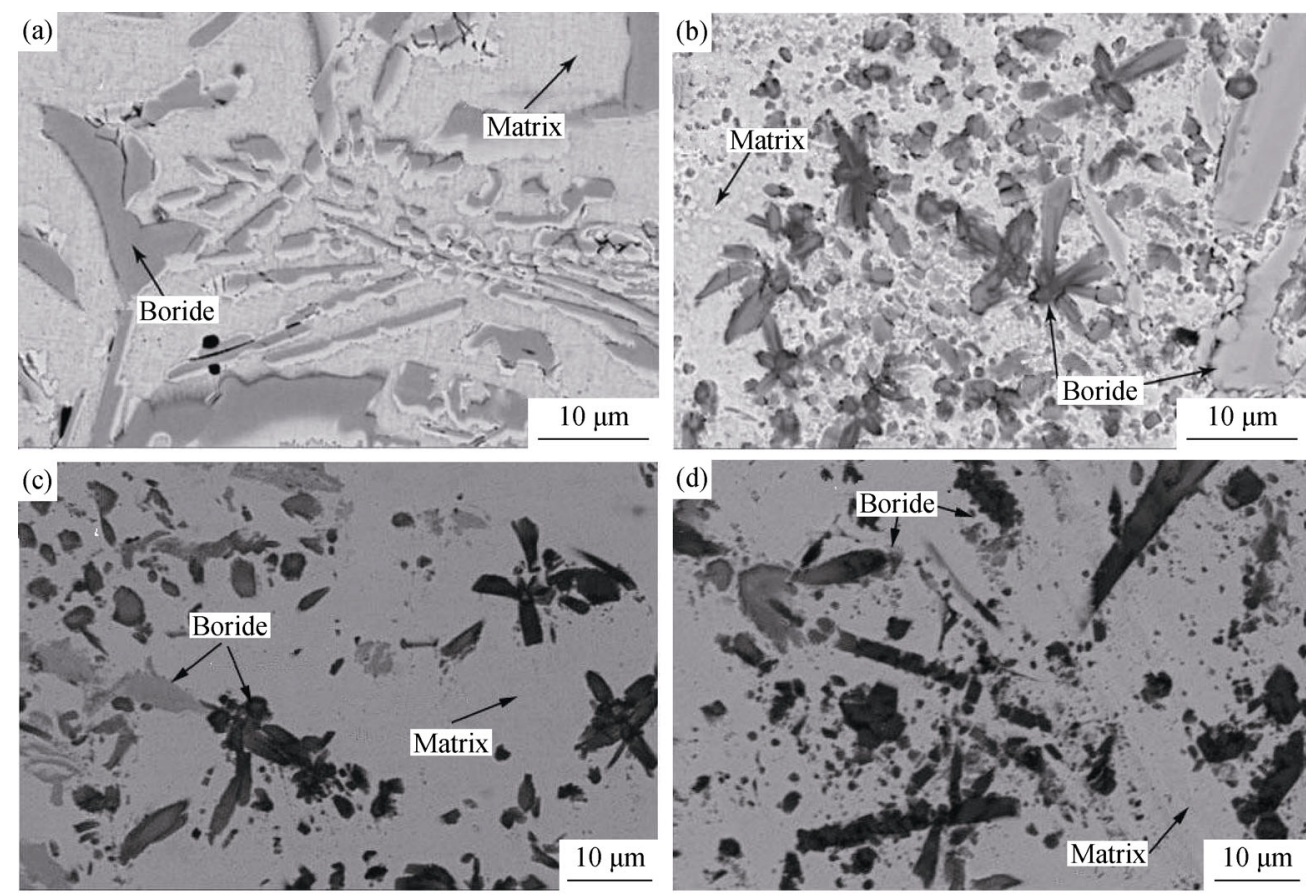

Fig. 1. SEM micrographs of the as-cast core layers with different titanium contents: (a) without Ti; (b) $2.2 \mathrm{wt} \% \mathrm{Ti}$; (c) $5.7 \mathrm{wt} \% \mathrm{Ti}$; (d) $7.9 \mathrm{wt} \% \mathrm{Ti}$.
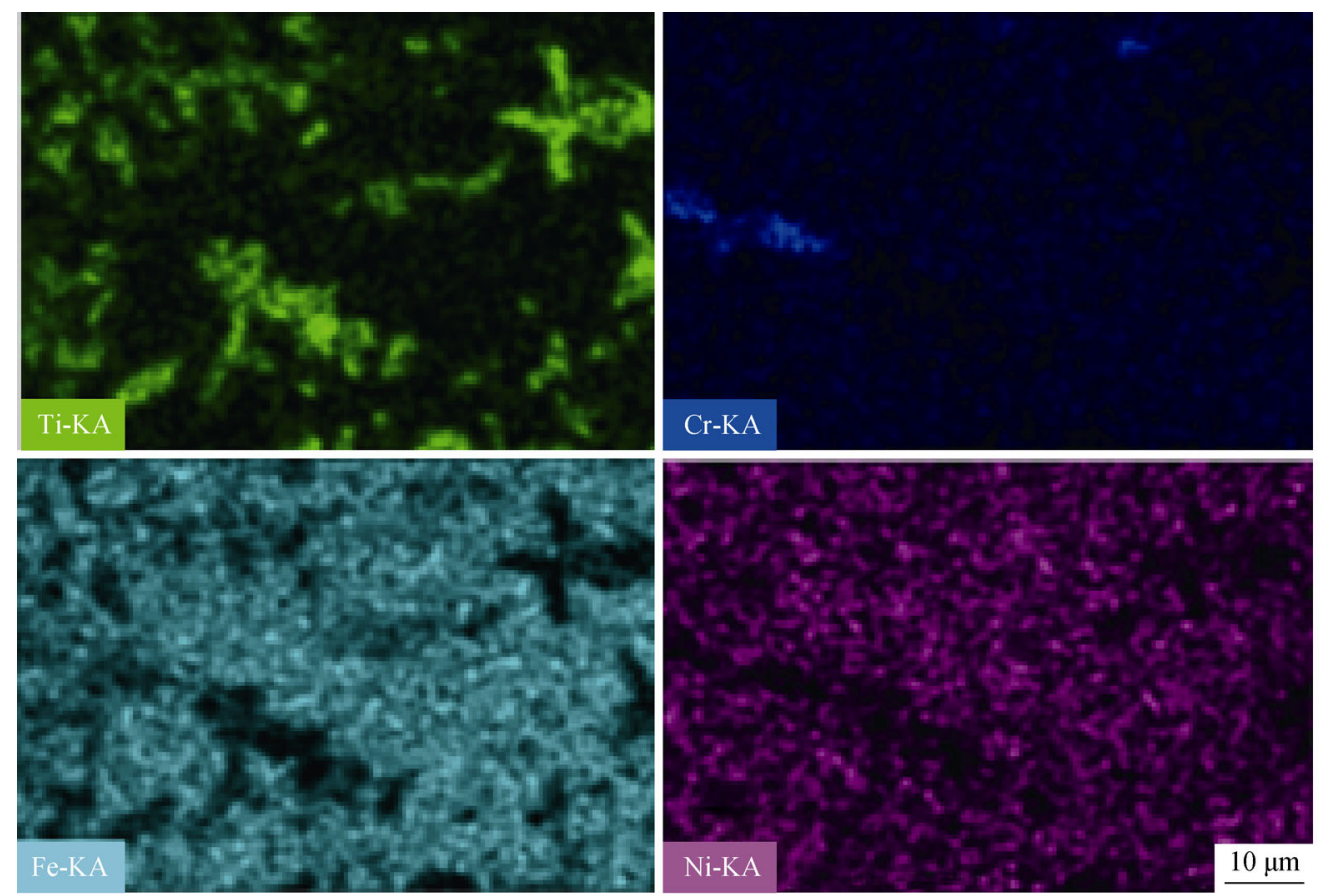

Fig. 2. EDS analysis results for the casting structure of the core layer of sample 3.

Some possible binary boride formations in the ternary $\mathrm{Fe}-\mathrm{Ti}-\mathrm{B}$ system are listed in Eqs. (2)-(5):

$\mathrm{Fe}+\mathrm{B}=\mathrm{FeB}$

$2 \mathrm{Fe}+\mathrm{B}=\mathrm{Fe}_{2} \mathrm{~B}$

$\mathrm{Ti}+\mathrm{B}=\mathrm{TiB}$

$\mathrm{Ti}+2 \mathrm{~B}=\mathrm{TiB}_{2}$
The results calculated according to the data of $\mathrm{Ye}$ and $\mathrm{Hu}$ [15] are shown below.

For reaction (2):

(3) $\Delta G_{T}^{\ominus}=-71128+5.452 T, \mathrm{~J}$.

(4) For reaction (3):

(5) $\Delta G_{T}^{\ominus}=-71128+3.779 T, \mathrm{~J}$. 

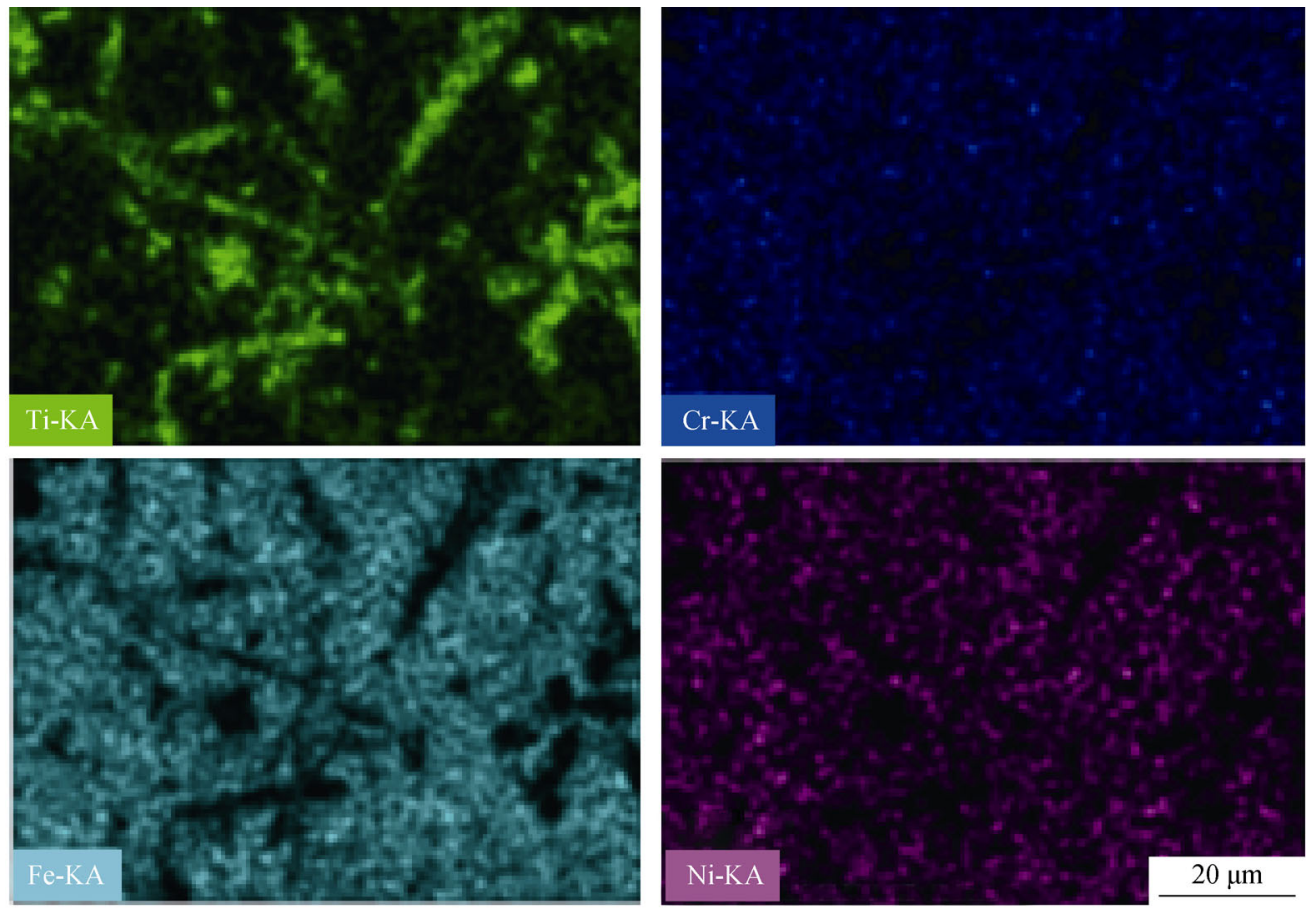

Fig. 3. EDS analysis results for the casting structure of the core layer of sample 4.

For reaction (4):

$\Delta G_{T}^{\ominus}=-160247+1.77 T, \mathrm{~J}$.

For reaction (5):

$\Delta G_{T}^{\ominus}=-323842+13.877 T, \mathrm{~J}$.

Reaction thermodynamics indicates that the compound with the maximal negative value of standard Gibbs free energy is first formed in the system composed of purely solid matter. Consequently, thermodynamically stable $\mathrm{TiB}_{2}$ was formed preferentially when $\mathrm{Ti}$ was added to the core material, and it could inhibit or even eliminate $(\mathrm{Fe}, \mathrm{Cr})_{2} \mathrm{~B}$ during the solidification of liquid alloy. This observation is consistent with the XRD analysis results. $\mathrm{TiB}_{2}$ precipitated first during solidification because of its high melting temperature, and it acted as a eutectic boride nucleus to refine boride particles [16].

\subsection{Hot rolling and heat treatment}

Fig. 4 shows SEM images of hot-rolled laminated plates with different titanium contents. The core was observed to be metallurgically bonded to the cladding through the processes of laminated casting and hot rolling. Most of the casting defects, such as porosity and blow holes, were simultaneously eliminated. Furthermore, the stress field generated at the interface during the rolling process was caused by the difference in deformation resistance between the cladding and the core.

Moreover, the long $(\mathrm{Fe}, \mathrm{Cr})_{2} \mathrm{~B}$ strips in the core layer of sample 1 were broken into small pieces after severe plastic deformation at high temperatures (see Fig. 4 (a)). As the Ti content was increased, some dark strips of petal-shaped $\mathrm{TiB}_{2}$ began to appear in the central layer. However, this structure was broken during rolling (see Fig. 4 (b)). The $\mathrm{TiB}_{2}$ phase in sample 3, which exhibited the smallest particle size and most uniform particle distribution among the investigated samples (see Fig. 4 (c)), should improve the mechanical properties of the high-boron steel. Furthermore, the neutron shielding effect is closely related to the boron distribution, and a dispersed boron phase could improve the shielding performance of the material. Some $\mathrm{TiB}_{2}$ blocks were observed in sample 4, which contained the highest concentration of titanium among the investigated samples (see Fig. 4 (d)), whereas the number of dispersed $\mathrm{TiB}_{2}$ particles decreased. As a consequence, the distribution uniformity of the boron phase changed. On the basis of the samples' microstructures, we concluded that the mechanical properties of sample 4 are inferior to those of sample 3. Additionally, the $\mathrm{TiB}_{2}$ phase in the casting structure was petal-like because of $\mathrm{TiB}_{2}$ crystal growth with preferred orientation. Through large deformation at high temperatures, the large petals of the $\mathrm{TiB}_{2}$ phase are broken into rods. The longitudinal axis direction of the rods becomes parallel with the rolling direction. In all of the samples, dispersed borides were observed in the area near the coating interface. The size of boride particles in the cladding was slightly larger in the case of sample 4. According to the EDS analysis results, the borides in 
the coating layers of samples 1 and 4 consisted of $(\mathrm{Fe}, \mathrm{Cr})_{2} \mathrm{~B}$ and $\mathrm{TiB}_{2}$, respectively. Thus, boron and titanium spread into the coating layer despite the limited solubility of boron in the matrix.

The hot-rolled samples were heat treated at $1100^{\circ} \mathrm{C}$ for $2-5 \mathrm{~h}$ and then quenched in water to ensure recrystallization of plastic grains and eliminate internal stress produced by deformation. In addition, the samples were subjected to a heat treatment. To investigate the influence of the Ti content and the heat treatment on the microstructure of the core layer, the volume fraction of boride (i.e., the area ratio of the metallographic cross-section) was determined according to
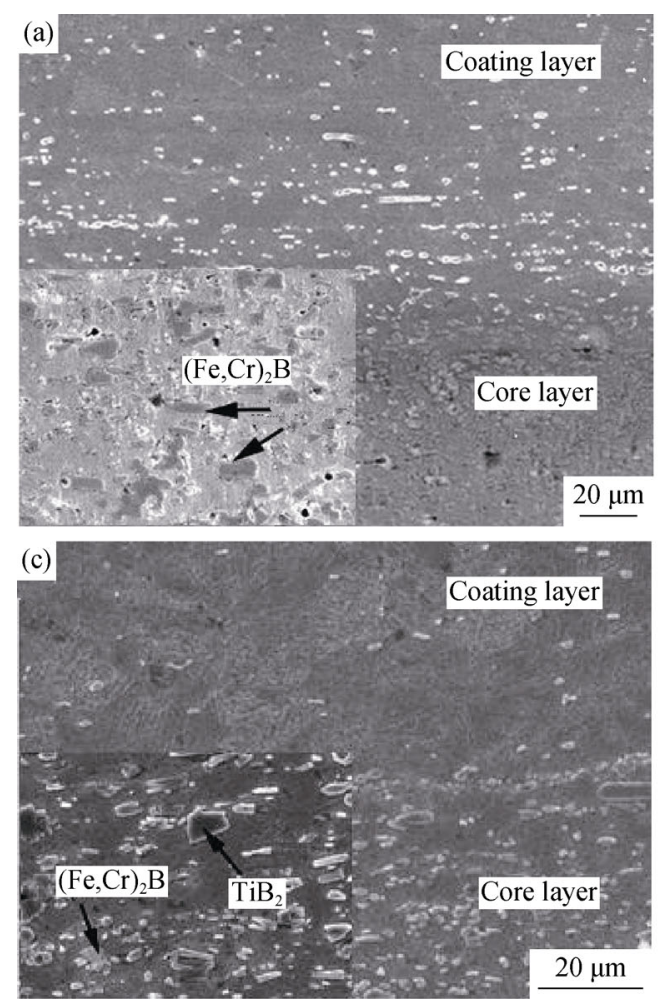

standard test method ASTM E562 [17]. The results indicate that the boride content decreases with increasing titanium content because of the formation of $\mathrm{TiB}_{2}$, which results in the formation of a smaller amount of the $(\mathrm{Fe}, \mathrm{Cr})_{2} \mathrm{~B}$ phase, as shown in Table 2. Theoretically, 2.25wt $\%$ B corresponds to $25.5 \mathrm{wt} \% \mathrm{Fe}_{2} \mathrm{~B}$, but only corresponds to $7.2 \mathrm{wt} \% \mathrm{TiB}_{2}$. However, the greater boride concentration in the core layer of sample 4 illustrates that the amount of $\mathrm{TiB}_{2}$ phase formed could increase when excess titanium was present. Furthermore, the boride content was slightly increased by the heat treatment but decreased slowly with increasing holding time.
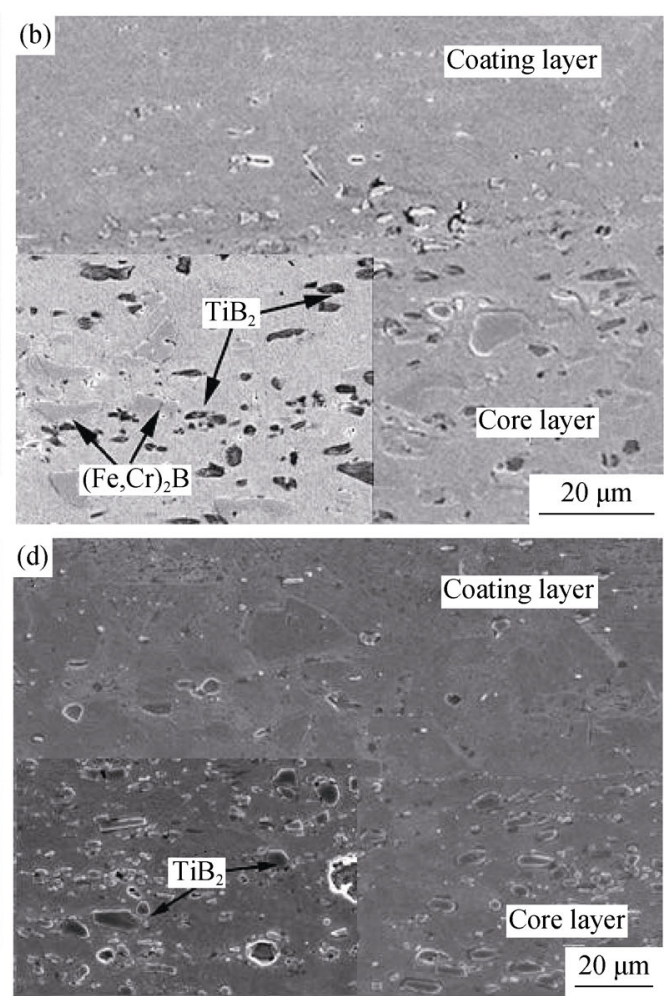

Fig. 4. SEM images of hot-rolled laminated blanks with different titanium contents: (a) without Ti; (b) $2.2 \mathrm{wt} \% \mathrm{Ti}$; (c) $5.7 \mathrm{wt} \% \mathrm{Ti}$; (d) $7.9 \mathrm{wt} \% \mathrm{Ti}$.

Table 2. Area ratio of boride in the core layer

\begin{tabular}{|c|c|c|c|c|}
\hline State & Sample 1 & Sample 2 & Sample 3 & Sample 4 \\
\hline Hot rolling & 36.22 & 29.03 & 15.32 & 18.00 \\
\hline $\begin{array}{l}1100^{\circ} \mathrm{C} \text { for } 2 \mathrm{~h} \text {, } \\
\text { water quenching }\end{array}$ & 43.30 & 35.50 & - & - \\
\hline $\begin{array}{l}1100^{\circ} \mathrm{C} \text { for } 3 \mathrm{~h} \text {, } \\
\text { water quenching }\end{array}$ & 42.67 & 32.25 & - & - \\
\hline $\begin{array}{l}1100^{\circ} \mathrm{C} \text { for } 4 \mathrm{~h} \text {, } \\
\text { water quenching }\end{array}$ & 42.33 & 31.02 & 16.10 & 18.28 \\
\hline $\begin{array}{l}1100^{\circ} \mathrm{C} \text { for } 5 \mathrm{~h} \text {, } \\
\text { water quenching }\end{array}$ & 41.47 & 31.13 & - & - \\
\hline
\end{tabular}

According to the classical theory of boride coarsening [18], the relationship between the size of boride particles and the heat-treatment holding time is determined as follows:

${\overline{R_{t}}}^{3}={\overline{R_{0}}}^{3}+K \cdot t$

where $\overline{R_{0}}$ and $\overline{R_{t}}$ are the average initial particle radius and the average particle radius at time $t$, respectively, when the system is in the asymptotic state, and $K$ is the rate constant associated with the increase of boride volume.

With extended holding time, the size of the boride particles slightly increased. Boride spheroidization or aggregation and growth make occur during holding process. 


\subsection{Mechanical properties}

The tensile properties of samples 1 and 2 under various conditions are shown in Fig. 5. Compared with the hot-rolling state of the high-boron steel, the strength and elongation of the high-boron laminated plates decreased and increased, respectively, after the heat treatment. The maximum elongation was obtained for the plates heat-treated at $1100^{\circ} \mathrm{C}$ for $4 \mathrm{~h}$.

Both hardness and strength of borated stainless steel are
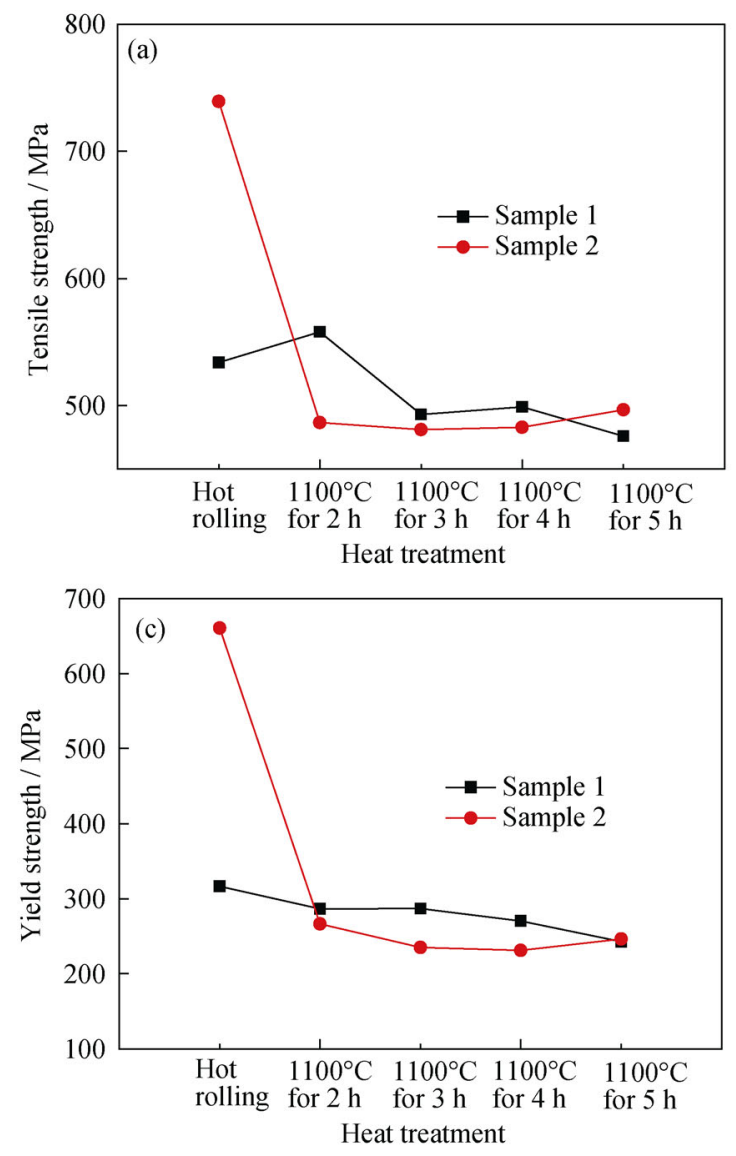

Samples 3 and 4 were heat treated at $1100^{\circ} \mathrm{C}$ for $4 \mathrm{~h}$ to investigate the effects of titanium content on the tensile properties of the material after heat treatment. With increasing Ti content, the tensile and yield strengths of the samples first increased and then decreased, whereas the trend of their elongation behaviors exhibited the opposite behavior, as shown in Fig. 6. Previous studies [5,19] have demonstrated that an optimum amount of added titanium exists for improving the properties of high-boron steel. Grebennikov et al. [5] indicated that the optimum amount of added Ti was 2.2B $+(1 \mathrm{wt} \%-1.5 \mathrm{wt} \%) \mathrm{Ti}$ in the case of titanium added to a boron-containing chromium-nickel steel. Liu et al. [19] reported that $\mathrm{Fe}-\mathrm{B}-\mathrm{Ti}$ alloys with a uniform microstructure and balanced mechanical properties were obtained when the titanium-to-boron atomic ratio was 0.5 . In the present inves- improved because of the distortion energy stored by the interstitial or substitutional solid solution formed by the reactions between boron and iron. The precipitates of $(\mathrm{Fe}, \mathrm{Cr})_{2} \mathrm{~B}$ and $\mathrm{TiB}_{2}$ distributed in grains and grain boundaries inhibit the dislocation motion, which results in the strengthening effect. The ductility of solution-treated samples was markedly increased; however, their strength decreased because of the reduction in the amount of the second phase formed in the matrix.

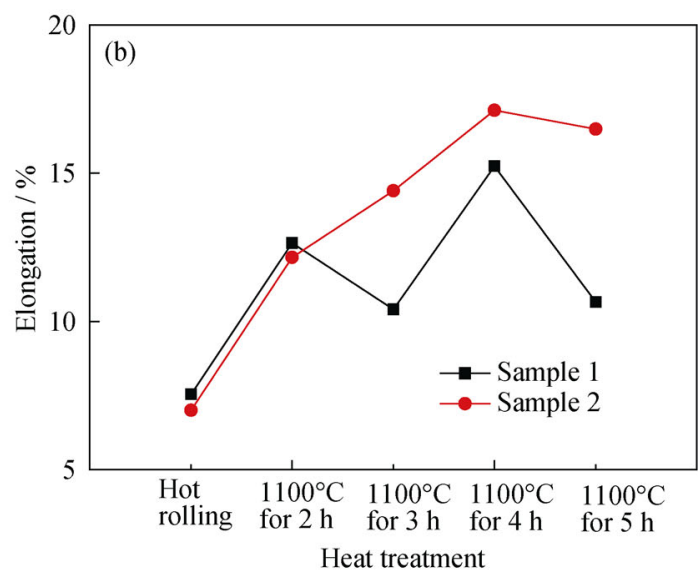

Fig. 5. Tensile strength (a), elongation (b), and yield strength (c) of samples 1 and 2 treated under different conditions.

tigation, the tensile strength, yield strength, and elongation of sample 4 after heat treatment at $1100^{\circ} \mathrm{C}$ for $4 \mathrm{~h}$ were 526.88 MPa, 219.36 MPa, and 29\%, respectively. These results indicate that each performance index could satisfy the requirements of the United States Standard for borated blanks [20]. Notably, the addition of excessive titanium improved the strength of high-boron laminated plates but decreased their ductility.

Figs. 7(a)-(c) show some cracks that appeared in the fracture morphologies of samples 1-3. These cracks could be due to the $(\mathrm{Fe}, \mathrm{Cr})_{2} \mathrm{~B}$ block, which causes cleavage or quasi-cleavage fracture. The number of cracks decreased with increasing titanium content, and the typical dimple pattern was observed in the fracture morphology of sample 3. As shown in Fig. 7 (e), the size of the dimples was 
strongly dependent on the distribution density of second-phase particles or precipitates. We observed that the outer side of the cladding exhibited a heavily dimpled morphology compared to the region near the interface, suggesting that this part of the plate was torn in a ductile manner. The tiny dimples in the core layer may be related to the dispersed boride precipitates. On the basis of these results, we concluded that the initial crack formed in the core layer and propagated to the cladding through the bonding interface. The well-transitioned layer near the interface indicates that the coating was metallurgically integrated with the substrate after laminated casting and hot rolling, as shown in Fig. 7 (e). As a consequence, no apparent separation was observed between the two layers after the tensile test.
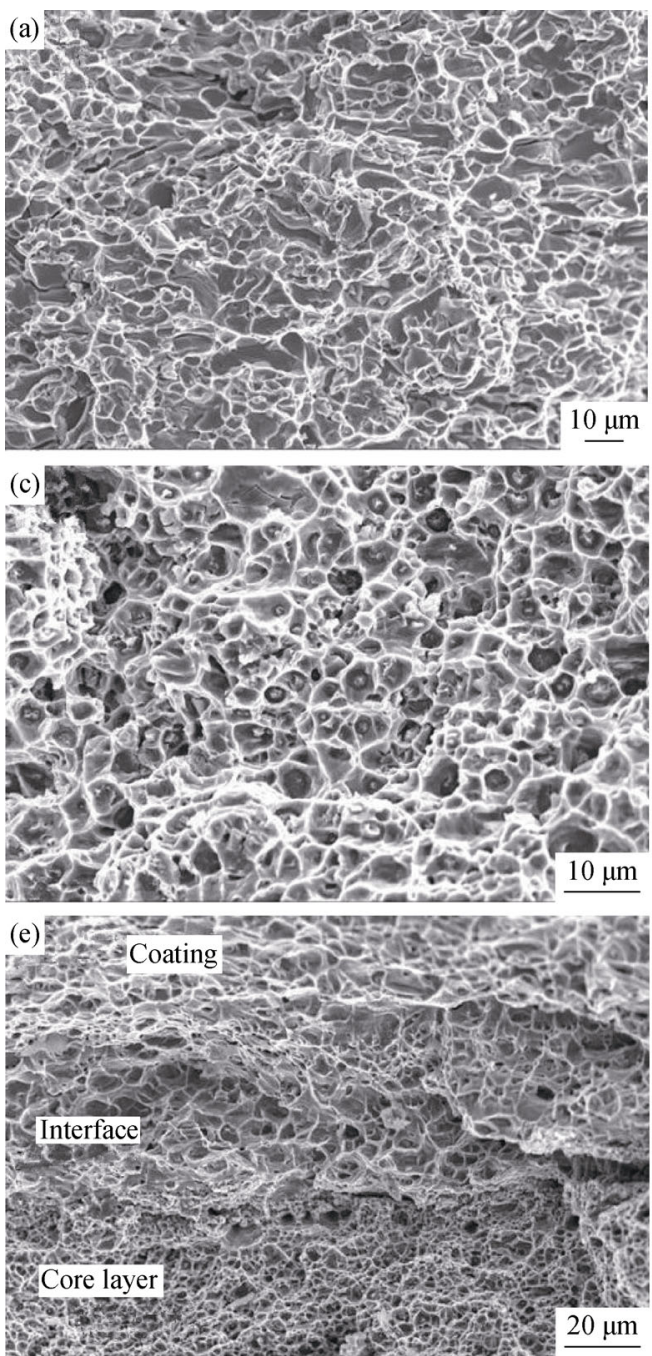

\section{Conclusions}

(1) High-boron laminated blanks were successfully fabricated via laminated castings combined with hot rolling.

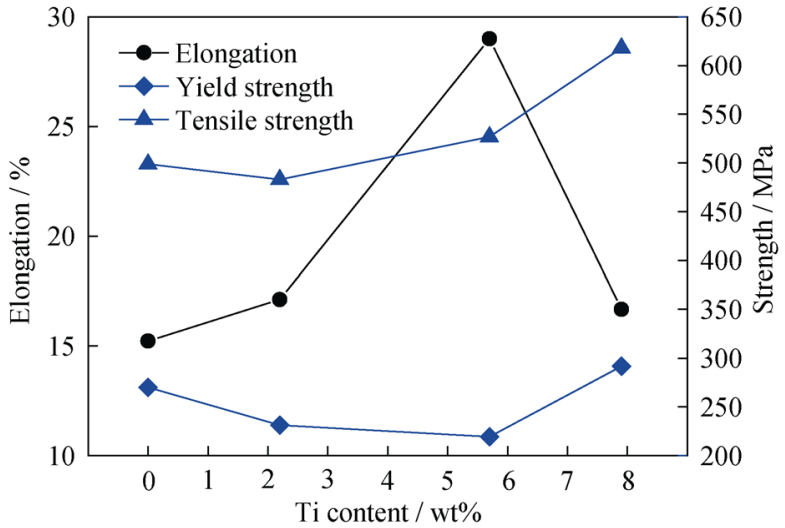

Fig. 6. Tensile properties of four groups of samples with different titanium contents after the samples were subjected to solution heat treatment $\left(1100^{\circ} \mathrm{C}\right.$ for $4 \mathrm{~h}$, water quenched).
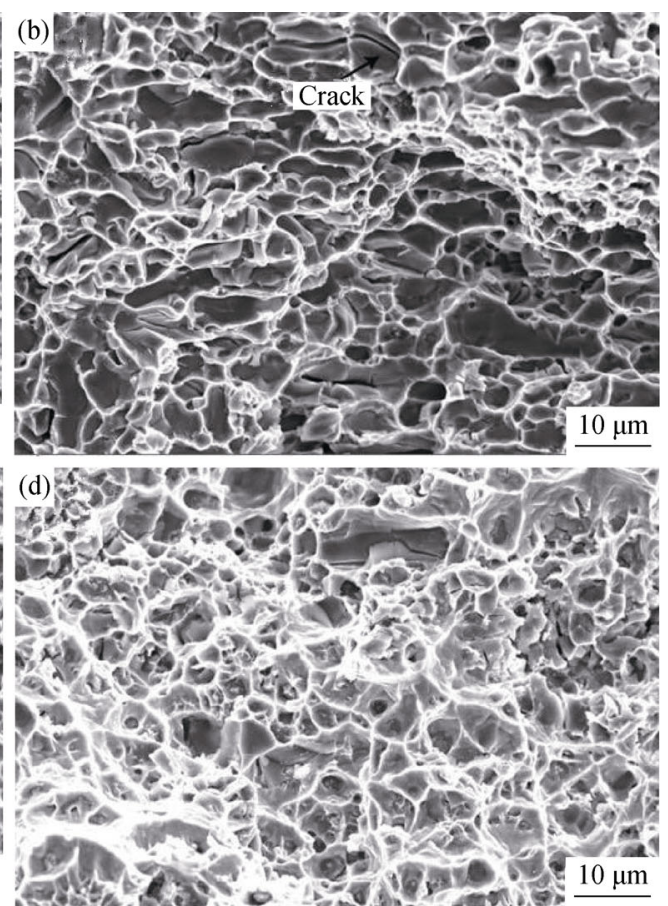

Fig. 7. Fracture morphology of samples subjected to heat treatment at $1100^{\circ} \mathrm{C}$ for $4 \mathrm{~h}$ : (a) core layer of sample 1; (b) core layer of sample 2; (c) core layer of sample 3; (d) core layer of sample 4 ; (e) interface of sample 3.

The casting defects were eliminated, whereas the long boride strips were broken into evenly distributed particles during hot rolling. In addition, good metallurgical bonding was obtained between the coating and the substrate. 
(2) The addition of titanium to high-boron laminated blanks improved the microstructure and properties of the material. Moreover, the optimum titanium content was determined to be $5.7 \mathrm{wt} \%$ for the high-boron steel used in this work, which contained $2.25 \mathrm{wt} \%$ boron.

(3) The ductility of high-boron laminated plates after an appropriate heat-treatment process $\left(1100^{\circ} \mathrm{C}\right.$ for $4 \mathrm{~h}$, followed by quenching in water) was greatly improved, and their mechanical properties satisfy the requirements of the standard ASTM A887-89.

Open Access This article is distributed under the terms of the Creative Commons Attribution License which permits any use, distribution, and reproduction in any medium, provided the original author(s) and the source are credited.

\section{References}

[1] D.S. McGregor, T.C. Unruh, and W.J. McNeil, Thermal neutron detection with pyrolytic boron nitride, Nucl. Instrum. Methods Phys. Res. Sect. A, 591(2008), No. 3, p. 530.

[2] A. Machiels, R. Lambert, Handbook on Neutron Absorber Materials for Spent Nuclear Fuel Applications, Electric Power Research Institute, 2005, p. 3-1.

[3] G. Wang, Y.G. Ding, J.S. Wang, X.F. She, and Q.G. Xue, Effect of carbon species on the reduction and melting behavior of boron-bearing iron concentrate/carbon composite pellets, Int. J. Miner. Metall. Mater., 20(2013), No. 6, p. 522.

[4] Z.L. Liu, X. Cheng, Y.X. Li, and K.H. Hu, High boron iron-based alloy and its modification, J. Iron. Steel. Res. Int., 16(2009), No. 3, p. 37.

[5] R.V. Grebennikov, A.V. Chirkin, V.N. Vukolova, T.N. Shavrova, and I.S. Balanik, Influence of titanium on the phase composition and deformability of high boron steels, Sov. At. Energy, 22(1967), No. 5, p. 481.

[6] P. Acosta, J.A. Jimenez, G. Frommeyer, and O.A. Ruano, Microstructural characterization of an ultrahigh carbon and boron tool steel processed by different routes, Mater. Sci. Eng. A, 206(1996), No. 2, p. 194.

[7] T.B. Sercombe, Sintering of freeformed maraging steel with boron additions, Mater. Sci. Eng. A, 363(2003), p. 242.

[8] E.M. Derun and A.S. Kipcak, Characterization of some boron minerals against neutron shielding and 12 year performance of neutron permeability, J. Radioanal. Nucl. Chem., 292(2012), No. 2, p. 871.

[9] G. Li, M. Jian, M.L. Wang, G.C. Wang, and X.Z. Liu, Research progress in neutron absorbers materials for reactor spent fuel storage and transportation applications, Mater. Rev., 25(2011), No. 7, p. 110.

[10] C.S. Liu, S.Y. Chen, Z.T. Wang, F.S. Chen, Y.X. Liu, D.K. Liang, and L.M. Xiao, Microstructure and properties of high boron bearing steel, Acta. Metall. Sin. Engl. Lett., 15(2002), No. 2, p. 248.

[11] J.A. Jiménez, G. González-Doncel, and O.A. Ruano, Mechanical properties of ultrahigh boron steels, Adv. Mater., 7(1995), No. 2, p. 130.

[12] H.G. Fu, Q. Xiao, J.C. Kuang, Z.Q. Jiang, and J.D. Xing, Effect of rare earth and titanium additions on the microstructures and properties of low carbon Fe-B cast steel, Mater. Sci. Eng. A, 466(2007), No. 1-2, p. 160.

[13] G.L. Xie, Research on the Processing and Application of New Type Laminated Composite Materials [Dissertation], University of Science and Technology Beijing, Beijing, 2011, p. 76.

[14] L.L. Yuan, J.T. Han, and J. Liu, Analysis of boride phase composition in high boron alloyed stainless steel containing titanium, Adv. Mater. Res., 941-944(2014), p. 226.

[15] D.L. Ye and J.H. Hu, Practical Handbook of Thermodynamic Data for Inorganic Compounds, 2nd Ed., Metallurgical Industry Press, Beijing, 2002, p. 1.

[16] L. He, Y. Liu, J. Li, and B.H. Li, Effects of hot rolling and titanium content on the microstructure and mechanical properties of high boron Fe-B alloys, Mater. Des., 36(2012), p. 88.

[17] ASTM E562-11, Standard Test Method for Determining Volume Fraction by Systematic Manual Point Count, ASTM International, West Conshohocken, USA, 2011.

[18] C.V. Robino and M.J. Cieslak, High-temperature metallurgy of advanced borated stainless steels, Metall. Mater. Trans. A, 26(1995), p. 1673.

[19] Y. Liu, B.H. Li, J. Li, L. He, S.J. Gao, and T.G. Nieh, Effect of titanium on the ductilization of Fe-B alloys with high boron content, Mater. Lett., 64(2010), No. 11, p. 1299.

[20] ASTM A887-89, Standard Specification for Borated Blanks, Sheet, and Strip for Nuclear Application, Annual Book of ASTM Standards, Philadelphia, USA, 2014. 